\title{
Vulnerability, Resiliency, and Dignity: Psychosocial Dimensions of the Refugee Experience
}

\section{INTRODUCTION}

\author{
Arancha Garcia del Soto
}

$\mathrm{W}$ ithin the realm of refugee work, "psychosocial" approaches tend to be labeled "soft" when compared to legal, economic, and medical perspectives. The term "psychosocial" itself encompasses many different ways of applying psychology and other social science knowledge, ranging from a clinical focus on individuals to broad community strategies. Often, professionals with shared backgrounds, such as psychologists, hold divergent beliefs and adopt different roles when employing psychosocial approaches in their work with refugees and survivors of violence. As one participant explained it at a meeting of psychosocial workers from Colombia, Sri Lanka, and Uganda, "It is not everything, but it is in every program." But in an effort to avoid the mere tokenization of words like "psychosocial," "participation," and "process," there are growing calls in the field for new ways of relating to and caring for refugees and survivors, listening more closely to their voices, and recognizing the specificities of the refugee context.

One of the founding fathers of participatory action research (PAR), Orlando Fals-Borda, argues that the three primary "strategic tensions" shaping how we work with populations different from our own involve ongoing debates about (1) theory and praxis, (2) the subject versus the object in research or applied work, and (3) cosmovision and value systems. Also, it can be argued that there are three different groups of interest, each requiring a different "lens," that converge when doing general refugee work. First, there are the refugees and survivors who want to have their basic needs met, strive to rebuild their lives, and demand justice and visibility. Second, there are the researchers and workers who want to understand the dynamics of conflict and recovery, and to implement programs. And third, there are the elites and institutions in charge of the "transitional" phase, eager to leave the violent times behind and to move forward (while often denying the survivors' right to memory). Although these three collectives agree on the basic goal of ameliorating the impact of violence, they usually differ-often considerably-in their understanding of what dignifies, who should define the needs, and how best to implement the programs.

The rigor of the validity-reliability dyad, and of evidencebased approaches more generally, is difficult to find in the field of applied refugee research and work. The "soft approaches" to research more commonly found here are guided by the complexity of the contexts and by the participation of the refugees themselves. It seems that it is often hard for some university scholars to understand this, given the priorities of their laboratories and classrooms when compared to the realities of the field.

In this issue, we present a collection of articles that represent a shared effort exploring how to better understand and communicate with the actors in the field, especially the refugees themselves, while also reflecting on the different narratives and tools that possible to do so (e.g., words and interviews, images, media articles, data). Together, these articles help move us toward thinking about the psychosocial perspective as a transversal approach, an approach that is an indispensable component of many programs regardless of their explicit focus, and an approach that is crucial in order 
to better grasp the culture, the values and priorities of the people, and the nuances of the refugee context.

Mike Wessells opens the conversation by acknowledging the critiques of the psychosocial approach for the absence of 'hard evidence,' and makes a clear and experience based plea for critical self-awareness, and for the specificity of action. He reminds us of the basics, which cannot be emphasized enough: local empowerment and the restoration of dignity, enhancing the importance of culture, and the need to avoid the imposition of outside approaches when working in refugee contexts.

In their contribution, clinical psychologists Roy Eidelson and Rebecca Horn focus on the individual and collective worldviews of Sudanese refugees in the setting of one of the largest refugee camps in East Africa, Kakuma Camp in Kenya, For over three years, Rebecca Horn was engaged in dedicated daily psychosocial work in the camp, while also collecting valuable data. Their article highlights the psychosocial crucial influences of context and culture in "meaning making." Along these lines, they explore the varying and profound meanings of 'home.'

Inmaculada Serrano bridges economic game theories approaches and the theory of emotions to formulate assessment tools that tap into the conceptions of displaced persons' decision to return to their places of origin in the areas of Zvornik and Vlasenica, in Bosnia-Herzegovina. Inmaculada is one of those young sociologists who has spent years in the field, and is able to combine an acute anthropological sensitivity with evidence-based approaches to research. The core sociological concept of her piece is 'microfoundations,' which is based on the material and emotional factors influencing decisions for and against return in this part of the Balkans.

Lakshmi Ramarajan represents the approach of organizational psychology. She analyzes the importance of human resources within the organizations implementing programs to assist refugees, specifically the role of a firm (an NGO) focused on working with refugees in Sierra Leone. The terms 'culture,' defining the institutional formal and not-so-formal regulations, and 'clients,' signifying the refugees, are central to her piece. Currently, conducts quantitative research, collecting data using identity questionnaires; she combines it with a deep understanding of applied work, coming from her several years of work with NGOs.

Laura Simich and her colleagues Lisa Andermann, Joanna Anneke Rummens, and Ted Lo, describe in their piece a clinical community workshop, held with members of the Toronto Tamil community following the Asian Tsunami. They emphasize the relevance of culture in the practice of 'disaster relief.' The authors highlight trust and mutual respect as the basic attitudinal messages; they also recall some of Jack Saul's and Daya Somasundaram's work, specifically their focus on 'dignity' and on the importance of culturally-sensitive and community-based approaches. They include several practical recommendations to conduct similar workshops, and make a final plea for cooperation among practitioners, institutions and the community.

Bree Akersson's article reflects on pregnant women and past and future ideas of vulnerability. Using a program of the International Rescue Committee (IRC) in the Northern Caucasus (Chechnya and Ingushetia) as an example, she provides a theoretical understanding of three types of social support systems in complex emergencies: material, cognitive, and emotional. She writes about the essential connections between this program and other related ones, such as post-partum care, gender-based violence prevention, and addressing pregnancies resulting from rape, pointing, as such, toward more solid and comprehensive strategies.

Serena Chaudry links the arts with the psychosocial approach, presenting an example of work that she conducted with Liberians in two scenarios: the U.S. and Liberia ('back home'). She describes this truly participatory Photovoice project, and the resulting multi-media exhibit, which included local artists and others. The key terms she emphasizes are 'resiliency' and 'giving back,' focusing especially on the elderly refugees.

Rosemary Barbera presents the psychosocial impact on communities of some of the political repression techniques used by the Chilean dictatorship - internal exile, or 'relegacion.' She describes the impact on the affected families from a social and political understanding of the dynamics of community. To her own insights from her long-standing, committed research in Chilean Human Rights, she adds examples from literature. Central to Barbera's piece is the idea that the real accountability lies in the memories of the so called 'clients' or 'beneficiaries,' in this case, 'los relegados' and their families.

Bruce A. Collet analyzes the notable tension between object and subject, the us vs. them, or insider-outsider gap that comes up when doing research with diasporic communities. He emphasizes the importance of understanding the deep meaning of 'community-based,' as connected to the trust issues between the researchers and the communities with which we want to work, the theoretical and applied principles of Participatory Action Research, and the need for the 'democratization of knowledge.'

Finally, Harold Bauder examines the processes of Canadian national identity formation through the media lens, in reaction to humanitarian immigration policies. Drawing on Hegelian dialectics, he uses a discourse analysis of newspaper articles published over the course of five years, which offer a body of illustrative case descriptions. He reflects on 
how the different social representations of refugees are connected to material and symbolic factors.

The majority of the authors have significant experience in this field, having had prolonged exposure to the various refugee populations worldwide. Some of the authors have years of field experience in the conflict zones of the world. They all encourage the adoption of a new "committed to the context" way of doing research and implementing programs, a way of working that basically "means/makes sense" to the so called 'beneficiaries.' They draw attention to the different generational, gender and vulnerable groups, in particular highlighting their resilience in the face of adversity (e.g. the strengths of the elderly or the pregnant women). The authors both listen to and reflect the voices of the refugees. Along the continuum between classic research and participation, they propose that the key issues should be addressed and resolved by incorporating the concepts and realities of the psychosocial aspects, to the current mainstream solutions being put forward.

Refugee populations worldwide experience pain, trauma and hardship. But also the resiliency required overcoming those and rebuilding life. Eradicating the injustices committed, and alleviating the sufferings of the refugees, is a common goal of both the refugees themselves, and the researchers and workers on refugee issues. Their shared commitment to this cause creates a bond between the two groups. Passion and suffering go together. Commitment and uncertainty is bond. We are still some steps away from achieving the goals of peace and dignity for all mankind, and the company of the survivors of the refugee experience will be essential in continuing this work. Their own voices, and the memories they will keep of our work when accompanying them in their hard march towards a more human life and freedom, represent the ultimate accountability, and the best possible testimony and evaluation of the importance of psychosocial processes.

Arancha Garcia del Soto is currently the Helen Hamlyn Senior Fellow at Fordham University's International Institute for Humanitarian Affairs (IIHA). Previously, she had been the Director of Refugee Initiatives at the Solomon Asch Center for the Study of Ethnopolitical Conflict at the University of Pennsylvania. She is a Social Psychologist, with a Ph.D. in Sociology from the University of Salamanca in Spain (1998), and has been cooperating with Universities in Colombia, Sri Lanka, Nigeria, Liberia, etc., since 2002.

Her research and applied work on emergency and development issues, have focused on psychosocial interventions involving survivors of violence (mostly community and gender based violence programs). It spans four continents, from Europe and Africa to Latin America and Asia. 